\title{
The Effects of Respiratory Training with Inspiratory Flow Resistive Loads in Premature Infants
}

\author{
SIDHARTHA TAN, SHAHNAZ DUARA, GALDINO SILVA NETO, MESFIN AFEWORK, \\ TILO GERHARDT, AND EDUARDO BANCALARI \\ Department of Pediatrics, University of Miami School of Medicine, Miami, Florida 33101
}

\begin{abstract}
Respiratory training of premature infants was performed to determine whether improved respiratory muscle strength and/or endurance would result. Twentytwo premature infants were randomized into control and training groups for $\mathbf{2} \mathrm{wk}$, using inspiratory flow-resistive loads for training $\left(75 \mathrm{~cm} \mathrm{H} O \cdot \mathrm{L}^{-1} \cdot \mathrm{s}\right.$ in wk 1 and $90 \mathrm{~cm}$ $\mathrm{H}_{2} \mathrm{O} \cdot \mathrm{L}^{-1} \cdot \mathrm{S}$ in wk 2). Respiratory endurance was assessed by the time interval required for the development of a 5 torr rise in transcutaneous $\mathrm{CO}_{2}$ tension during the hypoventilation induced by loaded breathing, using a moderately severe resistive load $\left(250 \mathrm{~cm} \mathrm{H} \mathrm{H}_{2} \mathrm{O} \cdot \mathrm{L}^{-1}\right.$. s at $\left.1 \mathrm{~L} \cdot \mathrm{min}^{-1}\right)$. Respiratory strength was assessed by the maximum negative airway pressure generated during occluded breaths, a pressure-time integral, and an effort index. Results revealed that respiratory muscle endurance, which was not initially different between control and trained groups, increased significantly after 2 wk in the trained group by $137 \%$ (median value, $p<0.05$ ), whereas it remained unchanged in the control group $(-24 \%)$. The trained group of infants also showed a significant decrease in baseline breathing frequency between the initial and final measurements taken 2 wk apart when compared with controls ( $p$ $<0.05$ ) and a lesser increase in inspiratory time with loading in the final measurement as compared with the initial value $(p<0.05)$. There was no significant difference between the control and trained groups in initial or subsequent measures of respiratory muscle strength. Inspiratory flow-resistive load training appears to improve the respiratory endurance of premature infants in whom respiratory muscle fatigue has been described to play a role in the development of respiratory failure. (Pediatr Res 31: 613618,1992 )
\end{abstract}

\section{Abbreviations}

$V_{T}$ tidal volume

$\dot{\mathrm{V}}_{\mathrm{E}}$, minute ventilation

EI, effort index

ET, endurance time

IRL, inspiratory flow-resistive load

MNAP, maximum negative airway pressure

PTI, pressure-time integral

$\mathrm{TcPCO}_{2}$, transcutaneous $\mathrm{CO}_{2}$ tension

$\mathrm{Ti}$, inspiratory time

Received March 8, 1991: accepted January 21, 1992.

Correspondence: Shahnaz Duara, M.D., Associate Professor of Pediatrics, University of Miami, Department of Pediatrics R-131, Division of Neonatology, P.O. Box 016960, Miami, FL 33101.

Supported in part by Children's Medical Services of Florida, NHLBI, HL-3687301 , and the University of Miami Project: New Born.
$\mathbf{V}_{\mathrm{T}} / \mathrm{Ti}$, mean inspiratory flow

Ti/Ttot, respiratory duty cycle

An initial report describing the benefit of respiratory muscle training in normal adults (1) was followed by beneficial effects being described in adults with chronic obstructive pulmonary disease $(2,3)$, normal elderly subjects (4), adults with chronic airflow limitation (5), and children with Duchenne muscular dystrophy (6). Respiratory muscle function has been shown to improve after a period of inspiratory muscle training with repeated exposure to IRL $(7,8)$, which is one of the mechanisms used for respiratory muscle training. However, excessively large loads may result in respiratory failure, as demonstrated by the ventilatory failure seen in neonatal piglets (9) and infant monkeys with extended loading (10).

Apnea of prematurity remains a significant clinical problem in the preterm infant. The paucity of fatigue-resistant, highoxidative muscle fibers in the respiratory muscles of premature infants (11) and the increased diaphragmatic work associated with chest distortion $(12,13)$ makes respiratory muscle fatigue a likely cause of respiratory failure in the newborn period (14-16). Therefore, it is reasonable to speculate that any intervention that improves respiratory muscle endurance and/or strength is of potential benefit to the preterm infant.

In adult sheep, a training regimen with IRL breathing improved both ventilatory performance and the oxidative enzyme profile of the diaphragm (7). Because the premature infant tolerates IRL breathing reasonably well (17), it appeared feasible to design a training regimen using IRL in this population.

We postulated that exposing preterm infants to a respiratory training regimen would improve their ventilatory performance and respiratory muscle function. The purpose of this study was to determine if ventilatory performance, respiratory endurance, and respiratory strength in preterm infants subjected to a training regimen with IRL improved in comparison to a control group of infants.

\section{MATERIALS AND METHODS}

Subjects and protocol. Twenty-two preterm infants were enrolled in the study after informed parental consent was obtained in accordance with the guidelines of the Committee for the Protection of Human Subjects in Research at the University of Miami. Eligibility criteria required the infants to be between 1.0 and $1.5 \mathrm{~kg}$ in weight at birth and appropriate for gestational age, under $21 \mathrm{~d}$ of age when enrolled, and free of lung disease and apnea and to successfully complete an initial laboratory evaluation of respiratory endurance to document their inability to tolerate a moderately large load of $250 \mathrm{~cm} \mathrm{H} \mathrm{H}_{2} \mathrm{O} \cdot \mathrm{L}^{-1} \cdot \mathrm{s}$ at $1 \mathrm{~L}$. 
$\min ^{-1}$ for $\geq 1 \mathrm{~h}$ without increasing $\mathrm{CO}_{2}$ tension by 5 torr. Enrolled infants were then randomly assigned to control $(n=11)$ or training $(n=11)$ groups by random pair assignment; their clinical characteristics are described in Table 1. The initial laboratory evaluation was repeated in both groups on two additional occasions, separated by 1 -wk intervals. For descriptive purposes, these three laboratory studies will be referred to as study 1,2, and 3, as illustrated in the experimental protocol (Fig. 1).

All laboratory evaluations commenced during quiet sleep, as defined by behavioral criteria (18). No sedation was used. The infants were placed in the supine position, with the head turned to the right and positioned neutrally by a sandbag placed behind the head and a blanket roll placed under the chin. Airflow was measured by a Fleisch 00 pneumotachograph and a Validyne (MP45; Northridge, CA) differential air pressure transducer attached to low dead space nasal prongs (Novametrix, Wallingford, $\mathrm{CT}$ ), with electronic integration of the flow signal to obtain tidal volume. Air leak was avoided by the use of petroleum jelly at the junction of the nares and the nasal prongs and by the investigator holding the infant's mouth closed. Esophageal pressure was measured by a water-filled 8 French catheter, with its

Table 1. Clinical profile of all infants in control and training groups (mean $\pm S D$ )

\begin{tabular}{lcc}
\multicolumn{3}{c}{ groups (mean \pm SD) } \\
\hline$n$ & Control & Training \\
\hline Birth weight $(\mathrm{kg})$ & 11 & 11 \\
Age at study $1(\mathrm{~d})$ & $1.260 \pm 0.160$ & $1.233 \pm 0.128$ \\
Gestational age $(\mathrm{wk})$ & $9.3 \pm 4.6$ & $8.6 \pm 3.8$ \\
Weight gain in 2 wk (g) & $31.3 \pm 1.5$ & $29.8 \pm 1.6^{*}$ \\
Males & $256 \pm 116$ & $253 \pm 106$ \\
Methylxanthine use & $2 / 11$ & $2 / 11$ \\
Ventilator use before study & $4 / 11$ & $4 / 11$ \\
Oxygen therapy before study & $4 / 11$ & $4 / 11$ \\
\hline
\end{tabular}

${ }^{*} p<0.05$.
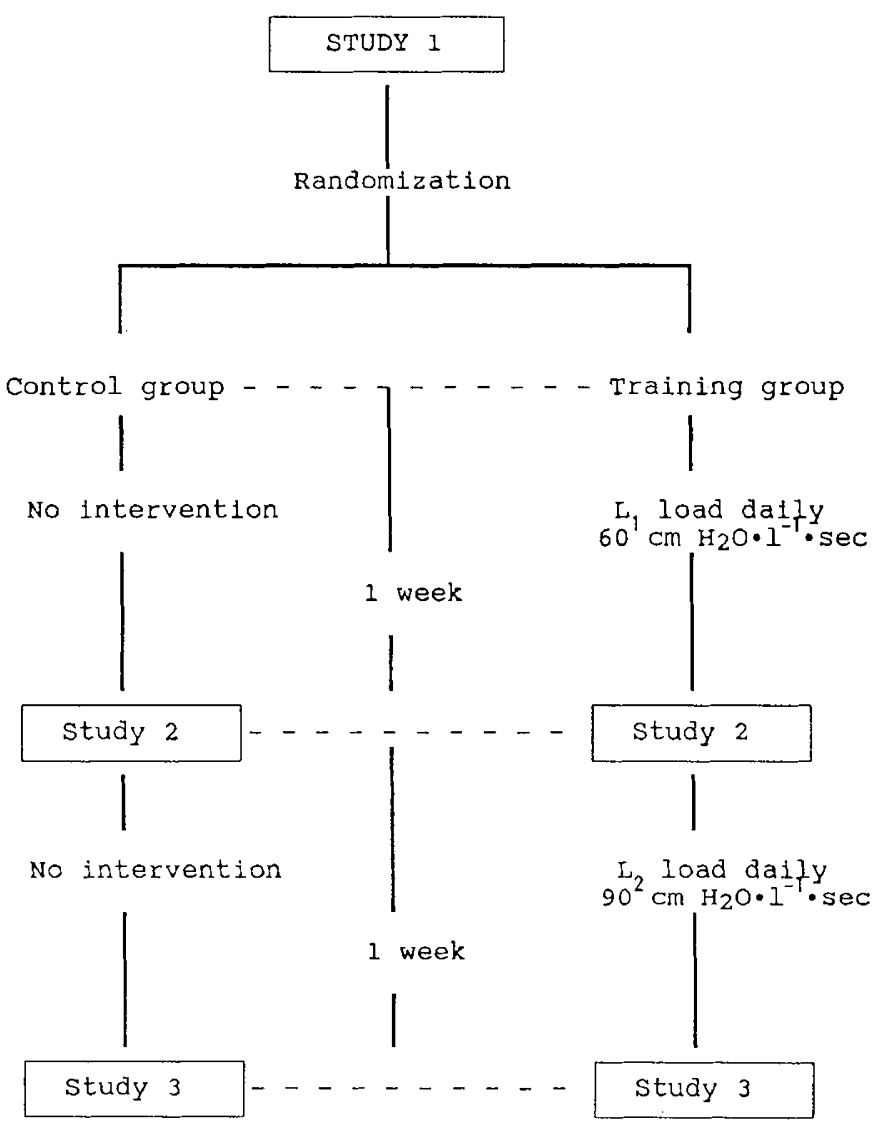

Fig. 1. Experimental protocol. distal end positioned in the lower third of the esophagus and connected to a hydrostatic pressure transducer (P23ID, Gould Inc., Cleveland $\mathrm{OH}$ ). Proximal airway pressure was measured by an air filled wide-bore catheter connected to a side port in the nasal prongs and attached to a Gould P23ID pressure transducer. Satisfactory placement of the esophageal catheter was verified by an airway occlusion maneuver done before each study (19). Oxygen saturation was measured by a Nellcor pulse oximeter (N100; Hayward, CA), and $\mathrm{TcPCO}_{2}$ was measured by a Novametrix 818 monitor at a temperature of $42^{\circ} \mathrm{C}$ throughout the study. This monitor was calibrated with standard $4 \%$ and $10 \%$ $\mathrm{CO}_{2}$ gas mixtures before each use and judged to be appropriate for the purpose of our study, inasmuch as similar monitors have been found to correlate satisfactorily with arterial $\mathrm{PCO}_{2}$ changes over a wide range of values in previous studies on healthy and sick neonates (20-22). All signals were recorded on a Gould 2800 multichannel recorder.

Measurements of ventilation, respiratory timing, and pulmonary mechanics were performed by following the study sequence outlined in Figure 2. Baseline measurements were repeated on steady state breathing shortly after the onset of inspiratory flow resistive loading (early IRL) and again before the cessation of the load (late IRL). Unless stated otherwise, all reported ventilatory data are early IRL values. A flow-resistive load of $250 \mathrm{~cm} \mathrm{H}_{2} \mathrm{O}$. $\mathrm{L}^{-1} \cdot \mathrm{s}$ at $1 \mathrm{~L} \cdot \mathrm{min}^{-1}$ was constructed from a narrow-bore plastic tube (23) and used as the test load in studies $1-3$. The load was attached to nasal prongs and pneumotachograph via the inspiratory limb of a low dead space, nonrebreathing valve (Hans Rudolph, Kansas City, MO), with a total system dead space of $3.3 \mathrm{~mL}$. After the initial measurements with loading were completed, the pneumotachograph was transferred to the inspiratory limb of the nonrebreathing valve to further reduce the system's dead space. The endurance protocol, which consisted of continuously applying the load until the infant developed a 5-torr
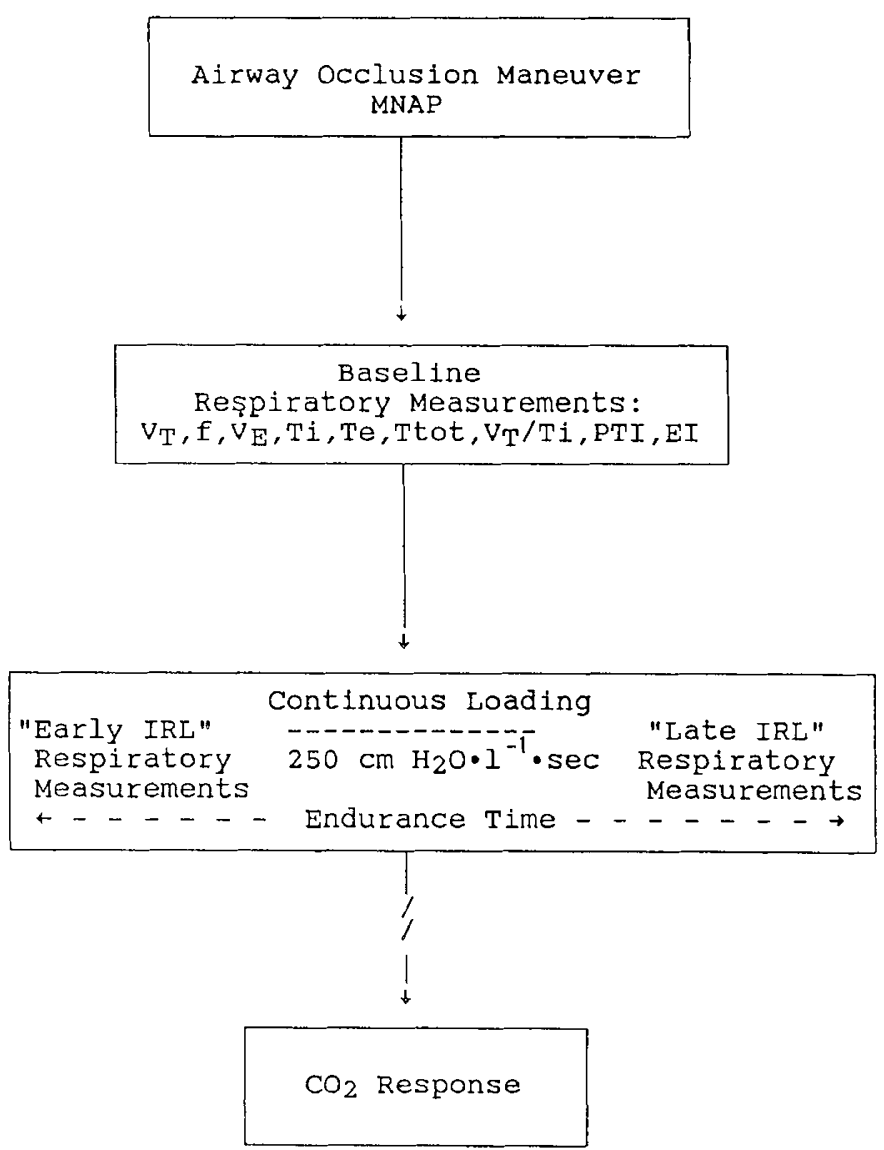

Fig. 2. Study sequence for studies 1,2 , and $3 . f$, breathing frequency; $T e$, expiratory time; and Ttot, respiratory cycle time. 
increase in $\mathrm{TcPCO}_{2}$ or a maximum duration of $1 \mathrm{~h}$ had elapsed (whichever point was first attained), was then commenced. Ventilatory and timing measurements were again performed immediately before discontinuation of the load (late IRL). The decision to discontinue loading in each infant was made by one investigator (G.S.N.), who remained blinded to the infants' study grouping for the entire duration of enrollment. Enrolled infants who tolerated the test load for a period of $\geq 1 \mathrm{~h}$ without developing a $\geq 5$-torr rise in $\mathrm{TcPCO}_{2}$ were considered tolerant of the test load and excluded from analysis under the endurance protocol.

$\mathrm{V}_{\mathrm{T}}$, respiratory rate, $\mathrm{Ti}$, expiratory time, respiratory cycle time, $\mathrm{Ti} / \mathrm{T}$ tot, and $\mathrm{V}_{\mathrm{T}}$ /Ti were calculated from 10 contiguous, regular breaths under baseline conditions and shortly after the onset of loading (early IRL). Values were averaged for regular breaths over $30 \mathrm{~s}$ in the period preceding discontinuation of IRL, because the pattern of breathing sometimes became terminally irregular (late IRL). Results from early IRL and late IRL were analyzed separately. Instantaneous $\dot{V}_{E}$ was obtained by multiplying the $V_{T}$ by the breathing frequency determined for these periods. Total pulmonary resistance was calculated by the method of Mead and Whittenberger (24), and dynamic lung compliance was also obtained (25) under baseline and loaded conditions.

Respiratory muscle endurance was estimated by measurements of ET (defined as the duration required by the infants to develop a 5-torr increase in $\mathrm{TcPCO}_{2}$ ) during the period of extended loading. This increase was arbitrarily chosen to represent onset of respiratory decompensation.

Respiratory muscle strength was estimated by MNAP, PTI, and EI. The MNAP was averaged from three end-expiratory airway occlusion maneuvers performed under baseline conditions. Each occlusion was maintained for three breaths, and the maximum negative pressure deflection obtained for each maneuver, usually during the third breath, was selected for averaging. The PTI was derived as the product of the peak to peak changes in esophageal pressure and Ti/Ttot $(26,27)$, determined for the same breaths used to determine $\dot{\mathrm{V}}_{\mathrm{E}}$ during baseline and loaded breathing; this is a modification of the method described in adults, necessitated by our inability to obtain maximum voluntary effort in the infants. The EI was obtained by summing up all peak to peak esophageal pressure deflections over 1 min under the same conditions and was used as another index of respiratory effort.

The ventilatory response to hypercapnia was determined at study 1 and study 3 in a subgroup of infants (six infants in the control group and five infants in the training group) to ensure that the ventilatory response to hypercapnia was not affected by the training regimen. Ventilation was determined by nasal prongs, a pneumotachograph, and a bias-flow circuit. Room air and $2 \%$ and $4 \% \mathrm{CO}_{2}$ (balance room air) gas mixtures were serially delivered through the system at a flow rate of $3 \mathrm{~L} \cdot \mathrm{min}^{-1}$, which exceeded the peak flow rate of the infants and prevented rebreathing. Infants were allowed to return to basal ventilation between $2 \% \mathrm{CO}_{2}$ and $4 \% \mathrm{CO}_{2}$. End tidal $\mathrm{CO}_{2}$ was measured by a mass spectrometer (Chemetron, St. Louis, MO) from a side port in the nosepiece. Steady state ventilation was usually attained after $3 \mathrm{~min}$ of gas inhalation. $\dot{V}_{E}$ was determined by averaging the $\mathrm{V}_{\mathrm{T}}$ and breathing frequency of all inspiratory $\mathrm{V}_{\mathrm{T}}$ in a 30-s period. The ventilatory response to $\mathrm{CO}_{2}$ in each infant was derived as the slope of the $\dot{V}_{E}$ per $\mathrm{kg}$ measured in room air, $2 \% \mathrm{CO}_{2}$, and $4 \% \mathrm{CO}_{2}$ obtained by linear regression.

All laboratory evaluations followed the sequence given in Figure 2. All respiratory tracings were reviewed by an investigator (S.D.) who was blinded to the intervention grouping of the study infants.

Training regimen. A flow-resistive load of $75 \mathrm{~cm} \mathrm{H}_{2} \mathrm{O} \cdot \mathrm{L}^{-1} \cdot \mathrm{s}$ at $1 \mathrm{~L} \cdot \mathrm{min}^{-1}$ was used for training in the first week of intervention, and a load of $90 \mathrm{~cm} \mathrm{H} \mathrm{H}_{2} \mathrm{O} \cdot \mathrm{L}^{-1} \cdot \mathrm{s}$ at $1 \mathrm{~L} \cdot \mathrm{min}^{-1}$ was used for training in the second week of intervention. These loads were of similar design to the test load. Their magnitudes were established on the basis of pilot studies done to determine load tolerance for an extended period of time (stable $\mathrm{TCPCO}_{2}$ and lack of arousal).

The training regimen required the selected load to be applied for $15 \mathrm{~min}$ on $\mathrm{d} 1,15 \mathrm{~min}$ twice on $\mathrm{d} 2$, and $15 \mathrm{~min}$ three times daily for $\mathrm{d} 3$ to 7 of that week. Training was done at the bedside using nasal prongs and a nonrebreathing valve, with the load attached to the inspiratory limb of the valve. Heart rate, $\mathrm{TcPCO}_{2}$, and oxygen saturation were monitored during the training periods. A training session was terminated and repeated later in the day if the infant aroused, the $\mathrm{TCPCO}_{2}$ rose $\geq 5$ torr above basal values, or the oxygen saturation fell below $90 \%$.

Statistical analysis. Statistical analysis was done by the paired $t$ test for comparison of the clinical profile and by the Fisher's exact test for comparison of the therapeutic interventions in the two groups. The Wilcoxon signed rank test was used for comparison of the percentage of change in ET between studies. Analysis of variance for repeated measures was used for betweengroup comparisons for the remainder of the ventilatory data. Linear regression was used to determine the slope of the ventilatory response to $\mathrm{CO}_{2}$.

\section{RESULTS}

All infants in the training group tolerated the intervention regimen. Of the 22 infants enrolled in the study (11 in each group), seven infants in the training group and eight infants in the control group successfully completed the entire protocol (Fig $3)$. Seven infants were excluded from the analysis of ET and ventilation for the following reasons: one infant from each group was disqualified because he or she failed to develop the 5-torr increase in $\mathrm{TcPCO}_{2}$ at the final laboratory evaluation (study 3 ) despite $1 \mathrm{~h}$ of loading, and two infants in the control group and three infants in the training group aroused during the final laboratory evaluation (study 3); their ET was labeled "arousal ET" and included in a separate analysis. Although these infants were excluded from the ET and ventilatory comparisons, their data were retained for evaluations of MNAP because this was not affected by interruptions during loading.

Both groups were similar in birth weight, interim weight gain during the study period, and chronologic age when first studied (Table 1), and no differences were apparent between the infants who failed to complete all three study trials and the larger group. The basal $\mathrm{TcPCO}_{2}$ values were also similar.

Of the trained group of infants $(n=7)$ whose ET could be examined, ET increased significantly from the initial to the final study, with the median (range) value increasing from 8.5 (4.7$18.2)$ min at study 1 and $7.0(1.8-44)$ min at study 2 to $20(7.8-$ 43.2) min at study 3. Conversely, the control group $(n=8)$ whose ET was examined had an initial ET of 4.1 (1.7-43) min at study 1 and $7.9(2.8-43)$ min at study 2, which remained essentially unchanged at $5.6(1.5-36.1) \mathrm{min}$ in study 3 . The percentage of change between study 1 and study 3 was determined by the following calculation: $\left(\mathrm{ET}_{\text {study } 3}-\mathrm{ET}_{\text {study } 1}\right) \times 100 /$ $\mathrm{ET}_{\text {study }}$. The median value of the percentage of change from study 1 to study $3(-24 \%)$ did not represent a significant change in the control group but was significantly increased in the training group $(137 \%, p<0.05)$. These differences are shown in Figure 4. If data on infants with arousal ET are included, the median percentage of increase in ET in the training group between studies 1 and 3 remained significantly prolonged $(104 \%, p<0.01)$. Six out of seven trained infants increased their ET over the 2 wk of the study, as compared to three out of eight infants showing a similar change in the control group. To rule out any influence from methylxanthine use, the eight infants who were not receiving the drug (five control and three trained) were compared with the seven infants receiving the drug (three control and four trained), and neither the ET at study 1 nor the percentage of increase in ET from study 1 to study 3 was different between the groups.

Respiratory muscle strength was not improved by the training 




Fig. 3. Schematic describing the ET outcome of the 22 enrolled infants.



Fig. 4. Group data representing the improvement in ET with training (median $\%$ change) over $2 \mathrm{wk}$ (study 1 to study 3$)^{*}, p<0.05$.

regimen. All 22 study infants ( $n=11$ for each group) were analyzed for changes in MNAP over time. MNAP increased similarly over time in both control and trained groups, from a mean $\pm \mathrm{SD}$ of $-9.8 \pm 2.1$ to $-14.7 \pm 3.3 \mathrm{~cm} \mathrm{H}_{2} \mathrm{O}$ between studies 1 and 3 in the control group and from $-11.5 \pm 3.6$ to $-19.8 \pm 8.4 \mathrm{~cm} \mathrm{H}_{2} \mathrm{O}$ between studies 1 and 3 in the trained group. PTI and EI, other estimates of respiratory muscle strength, were also not different between the groups at initial examination or over time.
Because the changes obtained with early IRL were not significantly different from the changes obtained with late IRL, we have limited our reporting to early IRL values (Table 2 ). Ventilatory changes were primarily those of respiratory timing. The trained group of infants showed a decrease in their baseline breathing frequency from $75 \pm 6$ to $66 \pm 7$ breaths/min between study 1 and study 3 , whereas the control group increased from $63 \pm 7$ to $79 \pm 9$ breaths/min $(p<0.05$, difference between groups). With loading, all subjects increased $\mathrm{Ti}$ above baseline values, with the control group showing a progressive increase from study 1 to 3 (69 to $75 \%>$ baseline Ti), whereas there was a decrease in the trained group (64 to $58 \%>$ baseline Ti) $(p<$ 0.05 , difference between groups). The remaining ventilatory parameters (respiratory cycle time, $\mathrm{Ti} / \mathrm{Ttot}, \mathrm{Vt} / \mathrm{Ti}$, and peak inspiratory flow) did not differ between groups, and the hypoventilation induced by loading was secondary to a fall in breathing frequency, whereas $V_{T}$ remained unchanged. Dynamic compliance and total pulmonary resistance were not different under baseline conditions, and the changes with loading or time were not different between groups.

The ventilatory response to $\mathrm{CO}_{2}$ was similar in both of the subgroups evaluated at studies 1 and 3. At study 1 , there was a slope of $0.026 \mathrm{~L} \cdot \mathrm{min}^{-1} \cdot \mathrm{kg}^{-1} \cdot$ torr $^{-1} \mathrm{CO}_{2}$ in the control group $(n=6)$ and $0.024 \mathrm{~L} \cdot \mathrm{min}^{-1} \cdot \mathrm{kg}^{-1} \cdot$ torr $^{-1}$ in the trained group $(n=5)$, which subsequently increased to $0.042 \mathrm{~L} \cdot \mathrm{min}^{-1} \cdot \mathrm{kg}^{-1}$. torr ${ }^{-1} \mathrm{CO}_{2}$ in the control group and $0.039 \mathrm{~L} \cdot \mathrm{min}^{-1} \cdot \mathrm{kg}^{-1} \cdot$ torr $^{-1}$ $\mathrm{CO}_{2}$ in the trained group by study 3 . The difference between groups was not significant.

\section{DISCUSSION}

The results of this study show that preterm infants respond to respiratory training with improved respiratory endurance. Training also decreased the baseline breathing frequency over time in comparison to controls, and lessened the prolongation of inspiratory time with loading, which may represent central adaptation. The similarity of $\mathrm{V}_{\mathrm{T}} / \mathrm{Ti}$ and ET between groups throughout the study period indicates that both groups were exposed to a similar magnitude of respiratory load and made a similar amount of respiratory effort.

The observation that a 2 -wk period of training was required for differences in endurance to be detectable is comparable to earlier data, by which it was shown that training regimens in adults extended to $4 \mathrm{wk}$ for detectable benefits (5) and a 3-wk period of training preceded demonstrable benefit in adult sheep (7). Our study was limited to $2 \mathrm{wk}$ after preliminary screening revealed that durations longer than this led to attrition of a substantial number of patients because of hospital discharge.

The clinical profile of the two groups of infants was similar in all respects other than gestational age, which by chance turned out to be somewhat higher in the control group. We do not believe that this small difference $(1.5 \mathrm{wk})$ influenced our current findings.

Although all study sessions commenced in quiet sleep, which was the state in which baseline measurements and the early response to loading were obtained, changes in sleep state during the prolonged endurance runs were unavoidable. Inclusion of a control group was done partly to address this event. More detailed separation of sleep state was not performed during individual runs, so the influence of changes in sleep state upon outcome cannot be commented upon.

The absence of a demonstrable improvement in respiratory muscle strength is also consistent with previous studies that showed that different types of training regimens were required for improvement of respiratory muscle strength than were needed for improved respiratory muscle endurance (8). However, the involuntary nature of our recordings did not allow a direct assessment of strength to be made, so that the lack of demonstrable improvement must be interpreted with caution. 


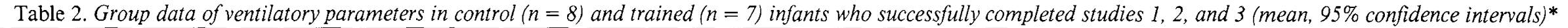

\begin{tabular}{|c|c|c|c|c|c|c|c|c|c|}
\hline \multirow[b]{2}{*}{ Group } & \multicolumn{3}{|c|}{ Study 1} & \multicolumn{3}{|c|}{ Study 2} & \multicolumn{3}{|c|}{ Study 3} \\
\hline & Baseline & Load & $\mathrm{D}$ & Baseline & Load & $\mathrm{D}$ & Baseline & Load & $\mathrm{D}$ \\
\hline \multicolumn{10}{|c|}{$\dot{\mathrm{V}}_{\mathrm{E}}(\mathrm{mL} / \mathrm{min} / \mathrm{kg}) \dagger$} \\
\hline Control & $439(531,347)$ & $305(359,251)$ & -28 & $490(554,426)$ & $362(403,321)$ & -22 & $534(694,375)$ & $396(452,341)$ & -20 \\
\hline Trained & $467(613,320)$ & $340(422,258)$ & -25 & $498(595,402)$ & $348(429,267)$ & -29 & $505(575,435)$ & $347(391,304)$ & -30 \\
\hline \multicolumn{10}{|l|}{$\mathrm{V}_{\mathrm{T}}(\mathrm{mL} / \mathrm{kg}) \dagger$} \\
\hline Control & $7.1(9.0,5.3)$ & $7.0(8.9,5.1)$ & 0 & $6.7(7.4,6.0)$ & $7.1(8.6,5.7)$ & 6 & $6.8(8.1,5.5)$ & $6.8(7.7,5.8)$ & 3 \\
\hline Trained & $6.5(8.0,5.0)$ & $6.6(8.5,4.8)$ & 1 & $6.0(6.9,5.1)$ & $6.6(8.0,5.2)$ & 10 & $7.9(9.6,6.1)$ & $7.3(9.1,5.5)$ & -7 \\
\hline \multicolumn{10}{|l|}{$\mathrm{Ti} /$ Ttot $\dagger$} \\
\hline Control & $0.43(0.48,0.39)$ & $0.53(0.57,0,48)$ & 22 & $0.44(0.48,0.41)$ & $0.54(0.59,0.49)$ & 25 & $0.45(0.49,0.42)$ & $0.60(0.63,0.58)$ & 33 \\
\hline Trained & $0.45(0.48,0.41)$ & $0.54(0.59,0.49)$ & 21 & $0.44(0.47,0.41)$ & $0.54(0.59,0.50)$ & 23 & $0.44(0.47,0.40)$ & $0.52(0.57,0.46)$ & 19 \\
\hline \multicolumn{10}{|l|}{$\mathrm{Ti}(\mathrm{s}) \ddagger$} \\
\hline Control & $0.42(0.49,0.36)$ & $0.72(0.85,0.59)$ & 69 & $0.37(0.43,0.31)$ & $0.63(0.72,0.55)$ & 72 & $0.37(0.46,0.28)$ & $0.62(0.71,0.54)$ & 75 \\
\hline Trained & $0.39(0.49,0.29)$ & $0.62(0.72,0.52)$ & 64 & $0.32(0.36,0.28)$ & $0.63(0.76,0.50)$ & 96 & $0.41(0.47,0.34)$ & $0.64(0.76,0.52)$ & 58 \\
\hline \multicolumn{10}{|c|}{ Breathing frequency§ } \\
\hline Control & $63(76,51)$ & $46(57,36)$ & -27 & $75(87,62)$ & $53(64,41)$ & -25 & $79(98,60)$ & $60(69,50)$ & -21 \\
\hline Trained & $75(87,62)$ & $54(67,42)$ & -24 & $84(97,71)$ & $54(69,40)$ & -36 & $66(79,53)$ & $50(62,39)$ & -24 \\
\hline \multicolumn{10}{|l|}{$\mathrm{V}_{\mathrm{T}} / \mathrm{Ti}(\mathrm{mL} / \mathrm{s} / \mathrm{kg}) \dagger$} \\
\hline Control & $17.1(21.2,13.0)$ & $9.8(11.9,7.6)$ & -41 & $18.6(20.8,16.4)$ & $11.2(12.4,10.1)$ & -37 & $19.9(24.9,14.8)$ & $11.0(12.4,9.5)$ & -41 \\
\hline Trained & $18.6(20.8,16.4)$ & $10.7(13.5,7.8)$ & -37 & $18.8(21.7,15.8)$ & $10.7(12.9,8.5)$ & -43 & $19.4(21.7,17.1)$ & $11.2(12.4,10.1)$ & -42 \\
\hline
\end{tabular}

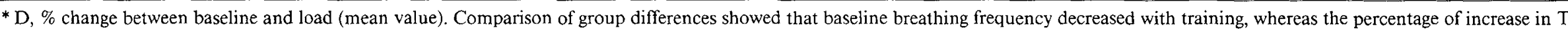
with loading was significantly lower in the training group by study $3(p<0.05)$.

$\dagger$ Group difference by baseline, NS; $\%$ change with load, NS.

$¥$ Group difference by baseline, NS; $\%$ change with load, $p<0.05$.

$\S$ Group difference by baseline, $p<0.05 ; \%$ change with load, NS. 
It is likely that the documented improvement in endurance in the trained infants was the result of improved respiratory muscle endurance. Despite our intent to train respiratory muscles, it is possible that differences were caused by other changes. The similarity of the ventilatory response to increased $\mathrm{CO}_{2}$ tension over the 2-wk duration in the two groups rules out the possibility that training caused differences in endurance because of changes in the ventilatory response to $\mathrm{CO}_{2}$. Second, the changes in intrinsic resistance with loading were similar in the two groups, ruling out the possibility that training modified extrathoracic airway stability, so that intrinsic resistance increased less with loading in the trained group and favored a longer ET (28). A final alternative for prolonged endurance could be a delayed rise in $\mathrm{CO}_{2}$ due to metabolic adaptation in the trained infants, which would allow a longer period of loaded breathing before increases in $\mathrm{CO}_{2}$ occurred. Adult sheep who were trained with inspiratory flow-resistive loading for $3 \mathrm{wk}$ showed less of an increase in $\mathrm{PCO}_{2}$ with loading and an increase in oxidative enzymes favoring fatty acid metabolism (7). A change in the dominant fuel substrate toward greater fat metabolism in the trained infants could lead to a similar slow rise in $\mathrm{CO}_{2}$. Although no differences were found in the interval weight gain during the study between the two groups, subtle differences in substrate use cannot be ruled out.

A reduction in physiologic dead space with training is an unlikely event, inasmuch as the decrease in $\dot{V}_{E}$ from baseline was secondary to a fall in breathing frequency, whereas $V_{T}$ remained unchanged in both groups. Other effects of training, such as differences in the central respiratory neural output or altered transmission at the neuromuscular junction of the trained infants, are also possible explanations and deserve further investigation.

The differences in baseline breathing frequency from study 1 to study 3 between the control and training groups are unlikely to be secondary to differences in sleep state because these were short runs that all commenced under the same conditions of sleep state. It is known that the breathing frequency response, unlike the $\mathrm{V}_{\mathrm{T}}$ response, is more variable in the neonate during the trigeminal stimulation that accompanies placement of any respiratory apparatus on the face (29). Our data do not allow us to conclusively state whether the differences in breathing frequency were a direct training effect or secondary to variability induced by respiratory apparatus.

Unfortunately, this population could not be studied under a controlled breathing strategy, so that differences in breathing frequency and respiratory timing over time may have benefited the trained group, and this possibility cannot be ruled out by our results. However, the fact that there was no difference between groups in the measurements of $\mathrm{V}_{\mathrm{T}} / \mathrm{Ti}$ at the final study and the similarities in EI between the two groups indicate that they both were exposed to similar magnitudes of loading. The improvement in ET is likely a reflection of intrinsic changes rather than the resuit of changes in breathing strategy, which have been shown to improve ET in adults with chronic obstructive pulmonary disease (30).

In summary, this study demonstrates that a respiratory training regimen in preterm infants using incremental inspiratory flowresistive loading over a 2 -wk period prolongs the ET of the respiratory system to extrinsic loads, whereas no changes are seen in respiratory muscle strength. Such intervention may have clinical implications in certain groups of infants, such as preterm infants who are ventilator dependent because of apnea secondary to peripheral respiratory pump failure.
Acknowledgments. The authors thank Susan Hilsenbeck for valuable advice regarding the statistical analysis and Madelaine Tamayo for technical assistance during the studies.

\section{REFERENCES}

1. Leith DE, Bradley M 1976 Ventilatory muscle strength and endurance training. J Appl Physiol 41:508-516

2. Belman MJ, Shadmehr R 1988 Targeted resistive ventilatory muscle training in chronic obstructive pulmonary disease. J Appl Physiol 65:2726-2735

3. Chen H, Dukes R, Martin BJ 1985 Inspiratory muscle training in patients with chronic obstructive pulmonary disease. Am Rev Respir Dis 131:251-255

4. Beiman MJ, Gaesser GA 1988 Ventilatory muscle training in the elderly. J Appl Physiol 64:899-905

5. Pardy RL, Rivington RN, Despas PJ, Macklem PT 1981 The effects of inspiratory muscle training on exercise performance in chronic airflow limitation. Am Rev Respir Dis 123:426-433

6. Martin AJ, Stern L, Yeates J, Lepp D, Little J 1986 Respiratory muscle training in Duchenne muscular dystrophy. Dev Med Child Neurol 28:314-318

7. Akabas SR, Bazzy AR, Dimauro S. Haddad GG 1989 Metabolic and functional adaptation of the diaphragm to training with resistive loads. J Appl Physiol 66:529-535

8. Pardy RL, Reid WD, Belman MJ 1988 Respiratory muscle training. Clin Chest Med 9:287-296

9. Maycock DE, Badura RJ, Watchko JF, Standaert TA, Woodrum DE 1987 Response to resistive loading in the newborn piglet. Pediatr Res 21:121-125

10. Watchko JF, Standaert TA, Mayock DE, Twigges G, Woodrum DE 1988 Ventilatory failure during loaded breathing: the role of central neural drive. J Appl Physiol 65:249-255

11. Keens TG, Bryan AC, Levison H, Ianuzzo CD 1978 Developmental pattern of muscle fiber types in human ventilatory muscles. J Appl Physiol 44:909913

12. Guslits BG, Gaston SE, Bryan MH. England SJ, Bryan AC 1987 Diaphragmatic work of breathing in premature human infants. J Appl Physiol 62:1410 1415

13. Heldt GP, Malcolm BM 1987 Distortion of chest wall and work of diaphragm in preterm infants. J Appl Physiol 62:164-169

14. Lopes JM, Muller NL, Bryan MH, Bryan AC 1981 Synergistic behavior of inspiratory muscles after diaphragmatic fatigue in the newborn. $J \mathrm{Appl}$ Physiol 51:547-551

15. Muller N, Gulston G, Cade D, Whitton J, Froese AB, Bryan MH, Bryan AC 1979 Diaphragmatic muscle fatigue in the newborn. J Appl Physiol 46:688695

16. Muller N, Volgyesi G, Bryan MH, Bryan AC 1979 The consequences of diaphragmatic muscle fatigue in the newborn infant. J Pediatr 95:793-797

17. Duara S, Abbasi S, Shaffer TH, Fox WW 1985 Preterm infants: ventilation and $\mathrm{P}_{100}$ changes in $\mathrm{CO}_{2}$ and inspiratory resistive loading. J Appl Physiol 58:1982-1987

18. Prechtl HFR 1974 The behavioral states of the newborn infant. Brain Res 76:185-212

19. Asher MI, Coates AL, Collinge JM, Milic-Emili J 1982 Measurement of pleural pressure in neonates. J Appl Physiol 52:49 I-494

20. Versmold HT, Severinghaus JW, Muller C, Paikert I, Riegel KP 1980 Transcutaneous monitoring of $\mathrm{PCO}_{2}$ in newborn infants. Pediatr Res 14:160A(abstr)

21. Brunstler I, Enders A, Versmold HT 1982 Skin surface $\mathrm{PCO}_{2}$ monitoring in newborn infants in shock: effect of hypotension and electrode temperature. J Pediatr 100:454-457

22. Bhat R, Kim WD, Shukla A, Vidyasagar D 1981 Simultaneous tissue $p H$ and transcutaneous carbon dioxide monitoring in critically ill neonates. Crit Care Med 9:744-749

23. Bennett ED, Jayson MIV, Rubenstein D, Campbell EJM 1962 The ability of man to detect added non-elastic loads to breathing. Clin Sci 23:155-162

24. Mead J, Whittenberger JL 1953 Physical properties of human lungs measured during spontaneous respiration. J Appl Physiol 5:779-796

25. Kreiger I 1963 Studies on mechanics of respiration in infancy. Am J Dis Child 105:439-448

26. Fishman A, Macklem PT, Mead J, Geiser SR (eds) 1986 Handbook of Physiology. The Respiratory System III. American Physiological Society, Washington DC, pp 511-527

27. Bellemare F, Grassino A 1982 Effect of pressure and timing of contraction on human diaphragmatic fatigue. J Appl Physiol 53:1190-1195

28. Duara S, Gerhardt T, Bancalari E 1987 Extrathoracic airway stability during resistive loading in preterm infants. $\mathrm{J}$ Appl Physiol 63:1539-1543

29. Dolfin T, Duffty P, Wilkes D, England S, Bryan H 1983 Effects of a face mask and pneumotachograph on breathing in sleeping infants. Am Rev Respir Dis 128:977-979

30. Belman MJ, Thomas SG, Lewis MI 1986 Resistive breathing training in patients with chronic obstructive pulmonary disease. Chest 90:662-669 